\title{
Inclusive campuses: Contributions from urban planning, architectural composition, and functional profile
}

The international university context is generating multiple dynamics of innovation. A relevant issue is the creation of inclusive campuses. This text studies keys to spatial planning on the urban and architectural scales and offers functional recommendations to create campuses that promote wellbeing and cognitive accessibility for people with intellectual disabilities. The goal is to inspire inclusive environments, promote an appropriation of the space, and reinforce a sense of belonging, emphasizing aspects such as the psychological and emotional perception of university environments. Based on this exploration, the text discusses a set of planning guidelines and architectural typologies with an inclusive scope. It begins by studying paradigms taken from the historical university legacy: the cloister and the campus. After this, the article focuses on aspects that inspire the integral planning of campuses to reinforce social inclusion: communities of learning, typologies of spatial composition, the human scale, edges, nature, the aesthetic component, and functional strategies. The text finishes by presenting a range of conclusions on how to supply those criteria and types so that campuses can be planned with higher quality with the goal of transforming them into inclusive environments, providing guidelines that can optimize them for all kinds of users.

Keywords: urban planning, architecture, university campus, social inclusion, intellectual disabilities 


\section{Introduction}

\subsection{Social inclusion and the university}

Any exploration of innovative strategies in terms of social inclusion must begin with a review of the theoretical background, focusing on the foundations of education. Delors et al. (1996) advocated the essential features of learning: knowing, doing, living, and being. Thus, the qualities that make campuses inclusive should integrate these four features. Transferring the plane of reflection to the universities, they must fulfil their three essential missions: education, research, and contribution to society. The third mission fully connects with social inclusion. Within the goals of higher education, personal development stands out (Bergan \& Damian, 2010). This fundamental objective must integrate all types of groups, addressing the most vulnerable ones with singular sensitivity. Moreover, social inclusion in university spaces aims to increase the presence of those with intellectual disabilities. Given that their characteristics limit that incorporation, inclusion encourages their active participation; because they enjoy the training that the institutions can provide them, one of the significant consequences is the opportunity to access the labour market. There are numerous social and educational initiatives that promote this mission, but the contributions of urban architectural solutions must be properly valued. Therefore, this text examines the built environment because it is called upon to enrich social inclusion and collaborate in creating academic environments that reinforce universal accessibility. Social inclusion requires a consistent educational effort that promotes the implementation of teaching and learning modalities and adequate training resources. Likewise, it is necessary to design welcoming protocols that favour the integration of students; the spatial dimension must also be added to the configuration of these "embracing protocols" through the composition of their shapes. Recently, valuable dynamics have been promoted, such as the "inclusive campus" or "campus without limits," together with public policies for social inclusion (Gorjón, 2020). As a result of increased awareness of this issue, various manuals and recommendations have been produced (Kleinert et al., 2012; Agarwal et al., 2015). Within the university landscape, the social inclusion of groups with intellectual disabilities suggests promoting participation and eliminating the multiple barriers that can generate exclusion. In parallel, training actions are needed so that professors can learn about inclusive educational strategies (Pijl et al., 1997).

\subsection{Social inclusion and human interaction with physical space}

Human behaviour can be internalized as the outcome of a dialogue between a person's personality and the environment. Social inclusion in education affects not only human attitudes, but also the built environment (Foreman, 2008; Mishchenko, 2013). Its growing dynamic in the international sphere is benefiting groups with disabilities (Molina \& Ríos, 2010). Starting from these dynamics, this text explores criteria and urban architectural solutions that promote social inclusion; in the case of university campuses, they constitute an essential factor for crystallizing learning communities (Harrington, 2014), thus helping their own academic success (Bogue, 2002). This issue is closely related to the experience of the environment of people with intellectual disabilities, linked to the creation of "places" (counting on the affective component) instead of "spaces" (mere built areas; Whitmer, 2009). It should be appreciated that people achieve wellbeing when they interact positively with the environment. Thus, people can be reflected in the environment, activating feelings of identity protection, control, and affection connected with space (Sommer, 1969; Proshansky et al., 1983). There is also the transcendence of the place: to promote social inclusion, it becomes vital to analyse the potential contributions of the physical space because it welcomes human contact, which fosters the true formation of a learning community. The place is thus claimed as a triggering factor for progress in knowledge.

\subsection{Perception and experience of urban architectural spaces}

Social inclusion affects the interaction between people and their constructed context, which influences their physical and mental wellbeing; it is based on the mechanisms of perception, both sensory and psychological. Sensory perceptions are channelled through the five senses, the most common being sight, hearing, and touch. From this, the interaction is conditioned by psychological perception, which shapes the sensations; environmental psychology deals with this specific matter (Canter \& Stringer, 1975). The context comes to mind translated into shapes, and on an urban and architectural scale there is a relationship between the design of a place and the mood of those that live in it: "buildings mold behavior" (Arnheim, 1977: 268). This introduces the emotional experience as a dimension that, transcending the strict perceptual sphere, awakens feelings; investigating these feelings uncovers ideation keys for educational venues. There is abundant literature on the importance of feeling when it comes to enjoying university complexes, and in planning itself through history (Giedion, 


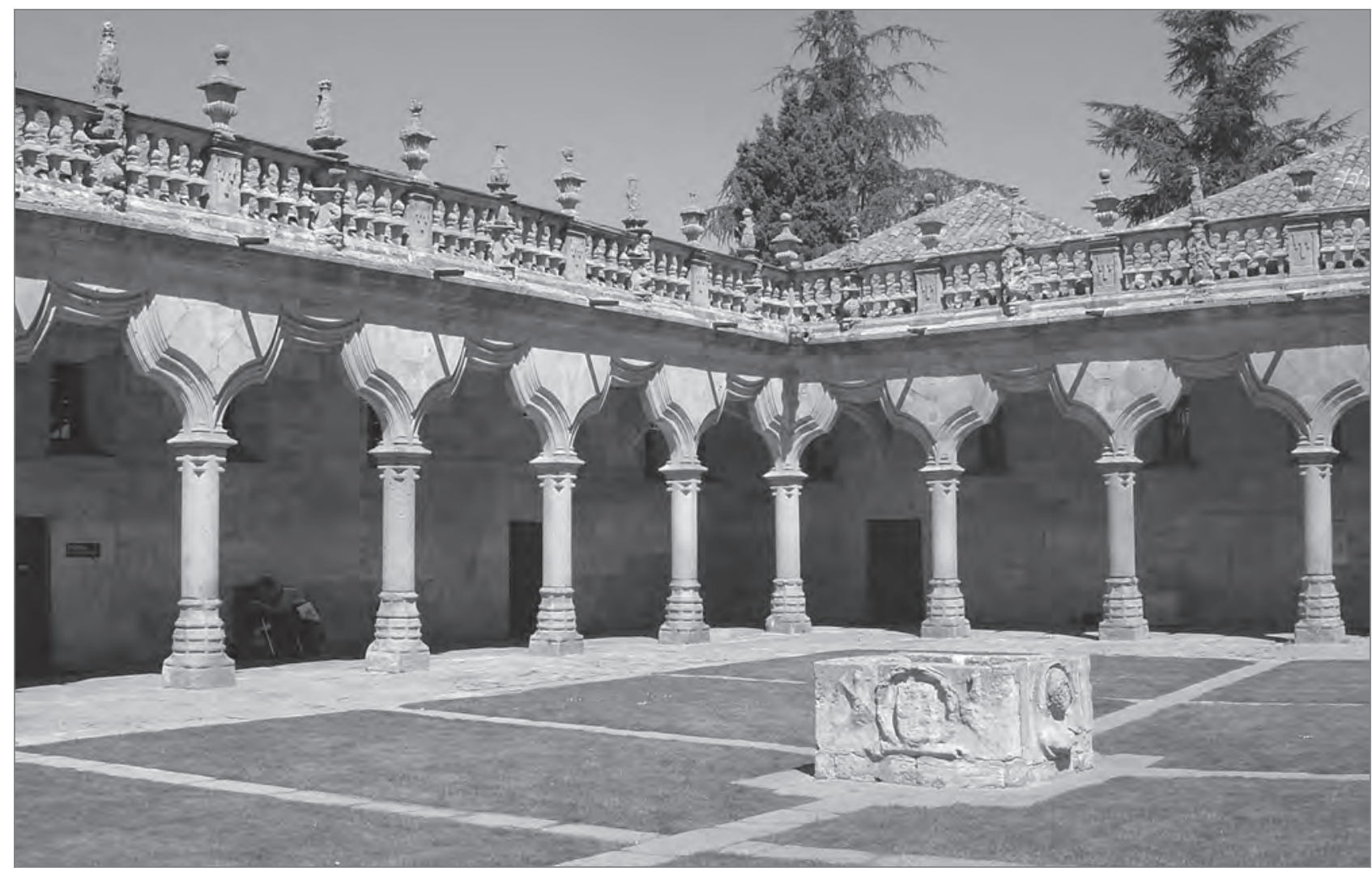

Figure 1: Cloister of the Minor Schools (Span. Escuelas Menores) in 2011, University of Salamanca, Spain (photo: author).

1982; Campos et al., 2020). Other studies have analysed the influence of the environment on people: Canter and Stringer (1975) proposed character, coherence, acceptability, flexibility, and security as important qualities; Kasmar (1970) referred to other qualities: aesthetic appeal, physical organization, or size. In people with intellectual disabilities, the perception and experience of physical spaces becomes an essential axis for devising design criteria that promote emotional wellbeing. Some evaluations have shown that users found more value in places that caused pleasant sensations; responses such as activation, excitement, liking, and relaxation were considered (according to the eight variables of the affective meaning of the environment; Russell \& Pratt, 1980). Such parameters are important for the social inclusion of these vulnerable groups because they have a sensitivity that is as valid as, or superior to, that of other groups. Having established essential bases for the perceptive and affective interaction between people and their urban architectural context, it is necessary to explore those characteristics that may suggest planning guidelines. Methodologically, in addition to a bibliographic investigation, this begins by analysing two historical university paradigms to extract readings that can inspire the ideation of inclusive campuses for people with intellectual disabilities today. Other contemporary strategies are added to these to set out a comprehensive list of planning criteria.

\section{Methods}

\subsection{The cloister as an architectural inspiration for social inclusion}

The cloister was born in a vocation of isolation with respect to its environment, aspiring to establish an intimate community. Starting from its genesis in monasteries and cathedrals, it was used as an architectural pattern in medieval European universities. Today extraordinary testimonies of its legacy remain at Oxford, Bologna, Cambridge, Salamanca, and Alcalá, among other institutions.

The concept of utopia has been an inexhaustible source of innovation at higher education institutions. Utopian attitudes can inspire the configuration of spaces for people with mental disabilities, fostering the search for a better society with social sensitivity. The concept of utopia promoted educational and spatial paradigms such as the cloister, which was consolidated as a place of hospitality, offering integration to foreign groups (O'Gorman \& MacPhee, 2006). It could thus be understood as an embryo of social inclusion. Functionally (as a consequence of the autonomous orientation of its monastic antecedents), the cloister represents the intention of self-sufficiency, although on campuses other facilities were added. 


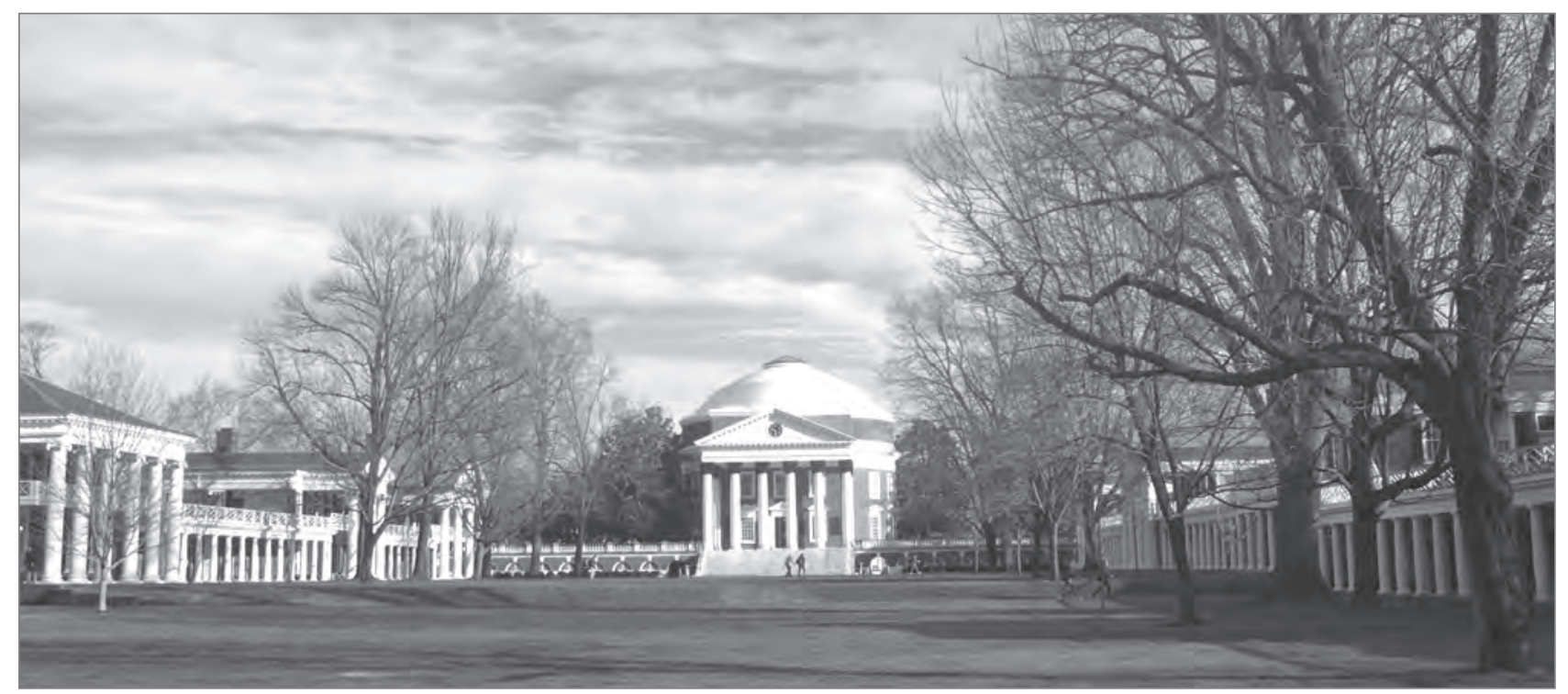

Figure 2: Campus of the University of Virginia in 2012 (photo: author).

In its composition, the cloister responds to a centripetal pattern, whose centre of gravity is an interstitial void. The built shape preserves a neat interior place, transmitting the sensation of spatial welcome and embracement. This perceptual consequence has led to various interpretations, such as psychologically considering the cloister as a "fostering mother" (Painter, 2003). In line with this intention to welcome, this spatial pattern reflects a commitment to the human scale (Coomans, 2018). It is also narrowly connected with the phenomenology of habitation and the poetics of space (Bachelard, 1958) Its architectural configuration is based on morphological solutions such as rhythmic arches of moderate height, as well as the use of the arch (semi-circular, lowered, or mixtilinear, among other models), which introduces a concave gesture into the vertical plane. The elegance of the simple shafts of the columns is offered as a sample of small scale, supporting a sequence of modulated arcades that delicately outlines the place where teachers and students wander around. The intimate vocation of the cloister is born from its own architectural apparatus, as a built framework that performs two concordant functions: isolation from the external context and protection of a self-absorbed interior, which favours the human encounter. Buildings and limits merge into a single reality: a delimiting volume that generates perceptual sensations of protection and shelter, underlining its inclusive vocation. Regarding the natural component, the cloister must be interpreted as a wisely conceived reality because it combines architecture and nature. The contributions of nature are of great value for social inclusion because certain elements are accommodated between the heavy walls and the delicate arches: a small meadow with grass, a tree, and water, whose delicate spring creates a landscape sound that favours concentration. Thus valued, nature increases the embrace that architecture itself provides with other resources.
As a result of a coherent compositional foundation, the cloister acquires a valuable aesthetic dimension. Evoking the historian Pevsner, Quaroni explains that the architectural structure evokes aesthetic perceptions in three concordant ways (which can be seen in these spatial solutions' structures): two-dimensional projection, where the facades are presented as vertical planes "in the manner of the painter"; three-dimensional projection, as a set of interlocking volumes, "in the manner of the sculptor"; and spatial projection, an exclusive feature of architecture because it concerns sequences of environments, expansions, or contractions of spaces, "in the manner of the architect" (Quaroni, 1977: 93). In all these projections, the user enjoys an immediate visual domain, which underlines their inclusive vocation.

In short, the cloister offers a historical lesson of suitability between the educational function and the planning of its built body, where people feel welcomed and embraced. It could even be understood that the delicate and rhythmic interior architecture is a kind of metaphor for the movement of those that inhabit it, on an intimate scale, reinforcing the feeling of social inclusion: "Bodies themselves generate spaces .... Consider, for example, the cloister, and the solemn pace of the monks who walk there" (Lefebvre, 1991: 216). Thus understood, the architectural composition of this outstanding typology would be the reflection of human walking, and the columns that flank the central void could be interpreted as its built echoes.

\subsection{The campus as urban inspiration for social inclusion}

If the cloister can be interpreted as the result of a utopian impulse translated into architecture, the campus is a translation 
into urban planning. Since its birth as an inheritance of the Oxonian colleges after they travelled to the New World, it has been historically consolidated as a model where education, living experience, and space converge. Its evolution has left emblematic samples in North American universities, such as Harvard University, the University of Virginia, Union College, or Stanford University, as well as in other locations, such as Otaniemi, Mexico City, Caracas, or the University City of Madrid.

In contrast to the European trend of university buildings integrated within urban cores, the campus emerged as a result of a segregating propensity, establishing itself as an "island of knowledge" in the territory. For this reason, the paradigm of the transoceanic cradle shares with the cloister the "utopia of insularity", whose origin is connected with the work of Saint Thomas More (Surtz, 1953). Regarding social inclusion, certain features of campus planning are apt to inspire it because the campus was a pioneer in the formation of an integral learning community (inclusive vocation orientation). The incorporation into the urban precinct of multiple functional facilities and equipment (those corresponding to the residential one being a highlight) confers a full experiential character, a habitat in itself. Certain plans have favoured the sense of welcoming and embracement, such as concentric designs, polarization around nuclei, green pedestrian areas, and a human scale. The arrangement around the quadrangle (a legacy of the British college) stands out as the centre of social gravity, which is a tributary of inclusion. The most relevant examples expressly highlight this cardinal element as an architectural symbol of institutional legitimacy and quality. The evolution in the planning of the campus entailed a progressive rupture of its primitive closure; at the heart of this gesture was the inclusive vocation for opening up to the social context. The quadrangle has always taken care of the human scale, resolving itself in accordance with these ordering guidelines: predominance of the central void as a natural environment that welcomes a human relationship, proportion between the dimensions of the architectural pieces and their distances, clarity of pedestrian paths, and the visual domain of the context, sometimes projected into broad perspectives.

Regarding the precinct edges, the campus has adopted various solutions, from rigid boundaries to diffuse ones. Rigid boundaries create two simultaneous sensations: on the one hand, visual and experiential containment, which transmits embracement and favours orientation, and, on the other, difficulty in expanding the terrain. Diffuse boundaries are usually justified by the adjacent presence of urban contexts, which favours interaction and - in a way - social inclusion itself. Painter highlights that the campus generates intellectual wellbeing through two positive emotions: "Humans sought a place that provided 'prospect' (the view over a long distance) and 'refuge' (a place to take shelter)" (Painter, 2003: 9). One component that permeates the personality of a campus is nature. Apart from providing a passive context of contemplation, it activates positive interactions with people (Kaplan, 1993). The experience of nature and green spaces offers mental benefits and affective responses (Houlden et al., 2018). This is related to walking as an activity that increases social inclusion because of the personal enjoyment that this experience of green areas implies (Speake et al., 2013). Nature provides great aesthetic energy, also influencing health and ecology. Its composition coordinated with architecture builds up an integral landscape that awakens positive emotions (Dober, 2003). It is important that green areas be accessible and close to teaching areas (Giles-Corti et al., 2005); this is also valued as a linking factor with the urban fabric.

In all this, planning is an inescapable quality. Its significance is such that it has been classified as a "work of art", endowed with its own aesthetic charge (Gaines, 1991). There are numerous testimonies regarding the transoceanic scenario, but it has also left brilliant examples on other continents, such as the Helsinki University of Technology, which Alvar Aalto designed in Otaniemi: "The quality of the scheme would have been evident in the preservation of the topography and vegetation to as great an extent as possible" (Hipeli, 2008: 19). Planning an organism as alive and changing as a campus requires paying special attention to the ideation of the general structure because it will transcend time: it is not a single object that is designed, but an entire process.

\section{Results and discussion}

\subsection{Social inclusion and urban architectural spaces: planning criteria and compositional typologies}

\subsubsection{Learning communities and utopian inspiration in planning}

The concept of utopia has always served as the energy of human progress since ancient times (Gray, 2012). In relation to social inclusion, its enormous potential must be used to illuminate the idea of inclusive campuses because secular values are fully in force today. The urban layout of a campus must respond to an intentional planning action that translates the ideals of the institution into tangible realities; this has happened especially in the North American scenario, where they reflected and transmitted these ideals, including how to configure true inclusive learning communities (Turner, 1984). In general, it has been shown that the quality in the planning of a campus has 
an impact on teaching quality itself and on the reinforcement of the sense of belonging in students (Coulson et al., 2010); all of this can be extrapolated to groups with intellectual disabilities. Social inclusion can be supported by the crystallization of experiential communities on university campuses, which create positive emotions and places of human closeness. The goal is to create welcoming, embracing, and friendly environments, which will foster feelings of psychological wellbeing, protection, and physical comfort.

\subsubsection{Typologies of formal composition}

Taking up the legacy left by the cloister and the campus in this matter, in the design of inclusive campuses those typologies of composition of a more centripetal nature should be chosen because they will favour the sense of welcoming and embracement on an urban and architectural scale. These will help groups with intellectual disabilities enjoy readability, in the sense of facilitating how each formal solution can be easily recognized, learned, and remembered. The goal is to plan inclusive campuses so that their shapes induce cognitive accessibility, a sense of protection, and intellectual wellbeing (Steel \& Janeslätt, 2017). Those centripetal solutions foster isolation, which aids social inclusion, as long as it creates an atmosphere of intimacy, activating experiences of spatial relations between people and the built environment taken as architectural objects.

Planning inclusive campuses must be done at various scales. This text essentially focuses on the urban and architectural scales, but the scale of the classroom should also be the object of this methodological approach. As pointed out by Jebril and Chen (2021: 1): "Studying the physical and psychological characteristics of children with mental disabilities reveals that there are architectural methods that must be considered before and during the architectural design of the classroom space, such as a U-shape in furniture arrangement, flooring, toilets, transition areas, foldable chairs, ceiling height, soft music, architectural insulation, ventilation, natural lighting, colors, and sunspace".

Certain planning guidelines have perceptual consequences that are relevant for social inclusion. Orthogonal grids establish a regular and proportionate order, although, to avoid disorientation in people with intellectual disabilities, it is appropriate to add codes of spatial differentiation through the use of singular places, colour or furniture. Likewise, the introduction of some iconic architectural elements helps fix references (the case of the Free University of Berlin, designed in 1963 by Candilis, Josic, and Woods, and the construction of the library by Norman Foster are interesting in this regard). The central configuration model responds to this quality of estab- lishing experiential and perceptual nuclei that activate feelings of integration. In terms of architectural composition types, the shapes that most promote cognitive accessibility, and the sense of protection and wellbeing are, in fact, centripetal; the ensembles inherited from the cloister and the quadrangle have given ample evidence of this over the centuries.

\subsubsection{The human scale}

People with intellectual disabilities are more comfortable in environments with a moderate scale and an intimate atmosphere because they promote feelings of embracement. When planning an inclusive campus, it is advisable to introduce the human scale as a general philosophy, whose value is demonstrated by paradigms such as the cloister (Masullo et al., 2020); this is also appreciated in the case of the campus. It fosters two convergent sensations that are suitable for reinforcing the social inclusion of vulnerable groups: refuge and perspective. According to research, both sensations have an ancestral origin (Winerman, 2004). In the situation at hand, a proactive analysis of a cloistered structure is quite useful because it is an outstanding pattern in terms of the connection between architectural shape and formative thought. Another strategy that is apt to promote social inclusion is the incorporation of informal common spaces that induce human interaction, transcending those of regulated education (Crook \& Mitchel, 2012).

Planning a campus with the intention of being sensitive to the human scale is a recommended resource for social inclusion, fostering individual identity. A basic aspect is the pedestrian profile. As lauded by scientists and even philosophers and poets, the experience of walking increases sensory enjoyment (a highly beneficial aspect for vulnerable groups; Giles-Corti et al., 2005). In Die Spatziergänge oder die Kunst spatzieren zu gehen (The Art of Walking, 1802), Schelle praised walking as an experience that unifies a merely mechanical action with another of an almost spiritual dimension. Walking evokes feelings of domesticity, and this enriches social inclusion. Pedestrian paths on campus guide and orient people with intellectual disabilities. The wellbeing they offer is also due to the fact that they treasure prehistoric evocations: some authors have argued that they are related to primitive human settlements (where following paths had finding food, water, or protection as a reward), and for this reason they activate positive psychological perceptions (Mithen, 1996). If these vulnerable people can make use of an organized signage system, along with coherent spatial sequences, they will access satisfactory space control. Among other things, the following elements that contribute to spatial orientation can be cited: facility layout, space differentiation, landmarks, signs, maps, and lighting (Carpman \& Grant, 2002). 


\subsubsection{Elements of the edge}

A limit is an element that must be expressly considered when designing inclusive campuses. Given the perceptual impact it can have on groups with intellectual disabilities, alternatives have to be weighed. In large complexes isolated from the city, the material clarity in the definition of the edge generates feelings of protection and reinforcement of the community. If a site is located adjacent to urban areas, permeable edges induce interaction with the environment, favouring integration and social synergies, as well as feelings of human and spatial inclusion. The manner of planning limits influences the social inclusion of these vulnerable groups because it evokes emotional responses. Planning should aim to eliminate physical barriers: they harm the level of participation because they hinder human interaction, the basis for such inclusion (Booth \& Ainscow, 1998). In small-scale areas or partial sectors of the campus, an edge should help the understanding of space and orientation, and not act as a physical barrier that causes isolation. The absence of impervious limits can be cognitively assimilated as a "spatial invitation" to entry. As a specific matter, it is advisable to plan entrances to the campus for people with disabilities that are not separated from the general entrance but together with it because this is in accordance with the principles of universal design and accessibility.

\subsubsection{Contributions of nature for social inclusion}

The presence of natural elements constitutes a very positive factor in the construction of campuses that favour the social inclusion of people with intellectual disabilities. Based on what has been learned from the cloister and the campus, it is easy to extrapolate the benefits derived from the enjoyment of nature because it contributes to the health and wellbeing of users (Thompson, 2010).

In an inclusive university campus, green areas play an important role in the crystallization of communities because they provide opportunities for relaxation, leisure, and social interaction. On the one hand, the works of various researchers indicate that the enjoyment of natural areas is beneficial for stress reduction (Ulrich et al., 1991). On the other, in group studies, students expressed that this enjoyment fostered social relationships, created places on campus as nuclei of integration, and prevented feelings of loneliness (Bell \& Dyment, 2008). When planning a campus that aims at the integration of people with intellectual disabilities, it is critical to include elements that foster a compositional dialogue with the architectural elements. In practice, such planning has to organize green areas, trees, other vegetation, and even water elements because they provide perceptual enjoyment based on aesthetic and emotional experience and are introduced into the university's everyday reality as symbols of the presence of life. One natural element that can increase the wellbeing of vulnerable groups on campus is the garden, in its various meanings (including curative; Lau \& Yang, 2009). It should be added that open spaces serve to guide people with intellectual disabilities because they link some buildings with others (Lau et al., 2014: 453; Garling et al., 1986). The aforementioned open spaces within campuses offer areas for human interaction and closeness (Chou et al., 2016). The use of central areas of quadrangles or gardens help people with intellectual disabilities integrate themselves in daily university life. There is a close relationship between architecture, nature, and people, for which it is necessary to devise inclusive campuses based on that nexus. Giedion (1982: 874) pointed out the following regarding architecture and its affinities with people and nature: "It exists to serve man, who is perishable as a plant. Thus, architecture also bears certain human and plant-like traits".

\subsubsection{The aesthetic component}

For a campus to reach levels of quality in terms of social inclusion, its built dimension must be the result of comprehensive planning work, which leads the design to its aesthetic culmination. This virtue should always be applied because it generates kind perceptions, mental wellbeing, and even feelings of happiness and calm (Weinberger et al., 2021). The planning process must consider the nuances of this topic, applicable to groups with intellectual disabilities, like all those that have been present in the paradigms analysed: the cloister and the campus. Two theoretical references illustrate the aesthetic relevance inherited from both formats. Lefebvre (1991: 217) added a suggestive vision of the cloister, associating it conceptually with feelings of individual happiness: "A space in which a life balanced between the contemplation of the self in its finiteness and that of a transcendent infinity may experience a happiness composed of quietude and a fully accepted lack of fulfilment". Le Corbusier, enamoured with the excellence of the American campus, described it as follows in When the Cathedrals Were White: "Everything is for the sake of calm and serenity. Each college or university is an urban unit in itself, a small or large city. But a green city. Lawns, parks, and a whole complex of comfortable quarters. . . The American university is a world in itself, a temporary paradise" (Le Corbusier, 1947: 135). Reviewing theories of architectural trends of the last century such as Art Nouveau or Expressionism, the shapes, textures, and colours of the material elements that surround human experience (such as architecture and nature) generate positive emotions in the people that experience them because they project their feelings onto objects of aesthetic potential. This is linked to the Einfüblung theory of subjective preferences (Worringer, 1959). Nature, already discussed above, adds another considerable aesthetic load as well. 


\subsection{Social inclusion: functional strategies in university campuses}

The previous sections examined the legacy left by the cloister and campus in terms of planning and spatial composition as an inspiring stimulus to design inclusive campuses today. However, there is a complementary plane of analysis that must be observed because it also provides guidelines for conceptualization: the functional profile. Functional aspects are addressed in this text because they have a component that affects the constructed dimension, and therefore they deserve to be considered as part of the university dynamics that promote social inclusion.

\subsubsection{Functional profiles for social inclusion}

If a campus has those facilities that give it the rank of a learning community (where residence plays an essential role), it enhances the social inclusion of all types of groups, including those with intellectual disabilities: "The ability of individuals to see their identity reflected in their surroundings is essential to creating an inclusive environment. Whether implicit or direct, aesthetics and campus history connote meaning and influence each individual's perceptions of welcome and belonging" (Clauson \& McKnight, 2018: 43).

A campus must have a comprehensive functional profile to host a learning community. Thus, it will be able to consolidate itself as a true habitat, where, in addition to academic activities, research, residence, leisure, sports, and social activities are housed. If this full experience is achieved, it will be easier to incorporate groups with disabilities because they will feel like true participants in student life. To achieve this goal, it is advisable to implement certain unique facilities specifically aimed at social inclusion. Some of them are meeting places or centres for vulnerable groups, as well as spaces for advice, guidance, and mentoring. Many international institutions have opted for these strategies, establishing the incorporation of new spaces to serve students with disabilities, so that they feel that they are not the object of discriminatory treatment within the community and that, on the contrary, their identity can be reinforced and recognized. Globally, these are spaces to promote human solidarity.

\subsubsection{Heritage contributions}

A valid strategy for social inclusion on campus that can be incorporated into urban and architectural planning is to enhance heritage. If planning aims to reinforce this aspect, it will enrich its educational and experiential potential because heritage is an effective transmitter of historical, artistic, and symbolic values. In terms of social inclusion, heritage elements help set guidelines for orientation and fix memory, both direct (arising from spatial experience) and cultural. The urban, architectural, or other modalities of heritage within a university complex become factors that contribute to the "place making"; that is, in building "places" instead of mere "spaces" as an effective quality to promote the wellbeing of people with intellectual disabilities.

\subsubsection{Participation in planning}

Experience shows the usefulness of planning through participation dynamics, which has very positive consequences both in the quality of planning itself and in the commitment of the members of the group, which ultimately implies a reinforcement of social inclusion: "When customers and citizens are openly enfranchised early in the design process and invited to assume creative and responsible roles, planners and architects suddenly find available to them undreamed of resources of local perception and wisdom, and the reinforcement of the community" (Sanoff, 1994: 4). Participation implies the involvement of groups interested in the university campus, and very singularly of vulnerable people and their relatives and friends, who will increase their feeling of belonging to the institution.

\subsubsection{Virtuality and social inclusion on campuses}

The current trend toward virtual teaching (increased as a consequence of COVID-19) should awaken certain reflections that are singularly important for the social inclusion of people with intellectual disabilities. Information and communication technologies (ICTs) can be great allies because they make possible the online delivery of academic content and activate places (previously inert) for alternative teaching/learning modalities (Méndez \& Cataldi, 2012). However, these virtual systems can never become a new educational paradigm. If this were the case, the human dimension that is inherent to integral training would be at risk. Likewise, it would damage the effective integration of vulnerable groups, for whom personal contact is an unavoidable value. A sound education cannot be achieved without counting on affective closeness between teachers and students, who must exercise empathy to build emotional bonds that reinforce cognitive ones. Interaction enriches social inclusion. As many education specialists have concluded, when learning in a group, higher levels of knowledge than the sum of the individual ones are reached; neuroscientists have also justified this, referring to the release of oxytocin and the activation of "mirror neurons" (Guastella et al., 2008). Sharing the university experience boosts the dopamine motivation system, fostering altruistic feelings (Rilling, 2002). Consequently, planning inclusive campuses must be sensitive to the risks that the abuse of the virtual can entail, 
but also insist on a reasonable proportion between virtuality and human contact (Chapman, 2006). Nevertheless, it must be never forgotten that the backbone of human education and social inclusion lies in human contact.

\section{Conclusion}

The essential purpose of this text is to provide guidelines for creativity related to planning inclusive campuses, where a human, formative, and spatial integration of people with intellectual disabilities is promoted. One of the most relevant conclusions is that, when devising them, one must start from a premise: spatial shapes condition behaviour (Burlage \& Brase, 1997). If every university complex must attain high levels of sensitivity toward the community that will inhabit it, this sensitivity becomes especially important when it comes to these vulnerable groups.

After the historical and conceptual journey carried out, a set of proactive readings can be extracted. In the first place, and because the methodology started by exploring past paradigms (the cloister and the campus), one conclusion is that, despite not having been devised with the purpose of social inclusion, the sensitivity and spatial validity of both models make them bearers of valid teachings for this mission. Designing inclusive campuses must be based on argumentative bases and concrete guidelines, but it also benefits from investigating the qualities that the cloister and campus have been shown to possess, as complexes that embrace formative human relationships. Second, these arguments are valid for devising spaces that generate mental wellbeing in people with intellectual disabilities, but they are also recommended for any group (Grigal et al., 2012; Bumble et al., 2018). In promoting social inclusion, special attention must be paid to the quality of the built environment, in the sense of recognizing how people emotionally respond to a given place, which becomes critical in vulnerable groups.

Finally, it is worth recalling the following reflection by Giedion (1982: 880): "All talk about organizing and planning is in vain unless we first create again the whole man, unfractured in his methods of thinking and feeling". Based on this, it can be affirmed (after carrying out a historical, proactive, and sensitive reading of criteria to reinforce social inclusion) that campus planning must always start from the human being, as the centre and axis of all thought and action.

Pablo Campos

CEU San Pablo University, Institute of Technology, Department of Architecture and Design, Madrid, Spain

E-mail: utoplan@telefonica.net

\section{References}

Agarwal, N., Moya, E., Yasui, N. \& Seymour, C. (2015) Participatory action research with college students with disabilities: Photovoice for an inclusive campus. Journal of Postsecondary Education and Disability, 28(2), pp. 243-250.

Arnheim, R. (1977) The dynamics of architectural form. Oakland, University of California Press.

Bachelard, G. (1958) La poétique de l'espace. Paris, Presses universitaires de France.

Bell, A. \& Dyment, J. (2008) Grounds for health: The intersection of green school grounds and health-promoting schools. Environmental Education Research, 14(1), pp. 77-90. DOI: 10.1080/13504620701843426

Bergan, S. \& Damian, R. (eds.) (2010) Higher education for modern societies. Competences and values. Strasbourg, Council of Europe Publishing.

Bogue, E. (2002) An agenda of common caring: The call for community in higher education. In: McDonald, W., et al. (eds.) Creating campus community, pp. 1-20. San Francisco, Jossey-Bass.

Booth, T. \& Ainscow, M. (eds.) (1998) From them to us: An international study of inclusion in education. London, Routledge.

Bumble, J., Carter, E. \& Bethume, L. (2018) Community conversations on inclusive higher education for students with intellectual disability. Career Development and Transition for Exceptional Individuals, 42(1), pp. 29-42. DOI: 10.1177/2165143418781303

Burlage, J. \& Brase, W. (1997) Campus architecture that shapes behavior. In: Keller, G. (ed.) The best of planning for higher education, pp. 114-119. Ann Arbor, MI, SCUP.

Campos, P., Wilson, R. \& Turner, P. (2020) Human imprint and spatial projection. An interpretation of the evolution of paradigms of university architecture as inhabited landscapes: quadrangle, yard, and campus. Space and Culture. DOI: 10.1177/1206331220916403

Canter, D. \& Stringer, P. (1975) Environmental interaction: Psychological approaches to our physical surroundings. Surrey, UK, Surrey University Press.

Carpman, J. \& Grant, M. (2002) Wayfinding: A broad view. In Bechtel, R B. \& Churchman, A. (eds.) Handbook of environmental psychology, pp. 427-442. New York, John Wiley \& Sons.

Chapman, P. (2006) American places: In search of the twenty-first century campus. Blue Ridge Summit, PA, Rowman \& Littlefield Publishers.

Chou, W. Y., Lee, C. H. \& Chang, C. Y. (2016) Relationships between urban open spaces and humans' health benefits from an ecological perspective: A study in an urban campus. Landscape and Ecological Engineering, 12, pp. 255-267. DOI: 10.1007/s11355-016-0295-5

Clauson, C. \& McKnight, J. (2018) Welcome to campus: Planning for diversity, inclusion, and equity. Planning for Higher Education, 47(1), pp. 39-48.

Coomans, T. (2018) Life inside the cloister. Leuven, Leuven University Press. DOI: 10.11116/9789461662606

Coulson, J., Roberts, P. \& Taylor, I. (2010) University planning and architecture: The search for perfection. London, Taylor \& Francis. DOI: $10.4324 / 9780203846353$

Crook, C. \& Mitchel, G. (2012) Ambience in social learning: Student engagement with new designs for learning spaces. Cambridge Journal of Education, 42(2), pp. 121-139. DOI: 10.1080/0305764X.2012.676627

Delors, J., et al. (1996) Learning: The treasure within. Paris, UNESCO Publishing.

Dober, R. (2003) Campus design. Ann Arbor, MI, SCUP.

Foreman, P. (2008) Inclusion in action. South Melbourne, Australia, Thomson. 
Gaines, T. (1991) The campus as a work of art. Westport, CT, Praeger Publishers.

Garling, T., Book, A. \& Lindberg, E. (1986) Spatial orientation and wayfinding in the designed environment: A conceptual analysis and some suggestions for post-occupancy evaluation. Journal of Architectural and Planning Research, 3(1), pp. 55-64.

Giedion, S. (1982) Space, time and architecture: The growth of a new tradition. Cambridge, MA, Harvard University Press.

Giles-Corti, B., Broomhall, M., Knuiman, M., Collins, C., Douglas, K., Ng, K., et al. (2005) Increasing walking: How important is distance to, attractiveness, and size of public open space? American Journal of Preventive Medicine, 28(2), pp. 169-76. DOI: 10.1016/j.amepre.2004.10.018

Gorjón, M. (2020) Políticas públicas en defensa de la inclusión, la diversidad y el género. Salamanca, Ediciones Universidad de Salamanca.

Gray, H. (2012) Searching for utopia. Oakland, University of California Press.

Grigal, M., Hart, D. \& Weir, C. (2012) Think college standards, quality indicators, and benchmarks for inclusive higher education. Boston, Institute for Community Inclusion.

Guastella, A. J., Mitchell, P. B. \& Mathews, F. (2008) Oxytocin enhances the encoding of positive social memories in humans. Biological Psychiatry, 64(3), pp. 256-258. DOI: 10.1016/j.biopsych.2008.02.008

Harrington, K. (2014) Community on campus: The role of physical space. Doctoral thesis. Atlanta, Georgia State University.

Hipeli, M. (ed.) (2008) Alvar Aalto. Helsinki, Alvar Aalto Foundation.

Houlden, V., Weich, S., Porto de Albuquerque, J., Jarvis, S. \& Rees, K. (2018) The relationship between greenspace and the mental wellbeing of adults: A systematic review. PloS ONE, 13(9), e0203000. DOI: 10.1371/journal.pone.0203000

Jebril, T. \& Chen, Y. (2021) The architectural strategies of classrooms for intellectually disabled students in primary schools regarding space and environment. Ain Shams Engineering Journal, 12(1), pp. 1-15. DOI: 10.1016/j.asej.2020.09.005

Kaplan, R. (1993) The role of nature in the context of the workplace. Landscape and Urban Planning, 26(1-4), pp. 193-201. DOI: 10.1016/0169-2046(93)90016-7

Kasmar, J. (1970) The development of a usable lexicon of environmental descriptors. Environment and Behavior, 2(2), pp. 153-169. DOI: $10.1177 / 001391657000200202$

Kleinert, H. Jones, M., Sheppard-Jones, K., Harp, B. \& Harrison, E. (2012) Students with intellectual disabilities going to college? Absolutely! Teaching Exceptional Children, 44(5), pp. 26-35. DOI: $10.1177 / 004005991204400503$

Lau, S. \& Yang, F. (2009) Introducing healing gardens into a compact university campus: Design natural space to create healthy and sustainable campuses. Landscape Research, 34(1), pp. 55-81. DOI: $10.1080 / 01426390801981720$

Lau, S., Gou, Z. \& Liu, Y. (2014) Healthy campus by open space design: Approaches and guidelines. Frontiers of Architectural Research, 3(4), pp. 452-467. DOI: 10.1016/j.foar.2014.06.006

Le Corbusier (1947) When the cathedrals were white. New York, Reynal \& Hitchcock.

Lefebvre, H. (1991) The production of space. Oxford, Blackwell.

Masullo, M., Castano, F., Toma, R. \& Maffei, L. (2020) Historical cloisters and courtyards as quiet areas. Sustainability, 12(7), pp. 1-21. DOI: $10.3390 /$ su12072887

Méndez, P. \& Cataldi, Z. (2012) Inclusividad en los campus virtuales: condiciones de accesibilidad y usabilidad. Revista Quaderns Digitals, 73(4). Available at: http://www.quadernsdigitals.net/datos/hemeroteca/r_1/nr_833/a_11233/11233.pdf (accessed 1 Jun. 2021).
Mishchenko, E. (2013) Towards inclusive campus environments: Evidence-based research of a university campus. Open House International, 38(1), pp. 31-42. DOI: 10.1108/OHI-01-2013-B0004

Mithen, S. (1996) The prehistory of the mind. London, Thames and Hudson Ltd.

Molina, S. \& Ríos, O. (2010) Including students with disabilities in learning communities. Psychology, Society \& Education, 2(1), pp. 1-9. DOI: 10.25115/psye.v2i1.431

O'Gorman, K. \& MacPhee, E. (2006) The legacy of monastic hospitality: 2 the lasting influence. Hospitality Review, 8(4), pp. 16-25.

Painter, S. (2003) Neuro-biology, species survival, \& campus spatial archetypes. Paper presented at the Conference of the Society for College and University Planning-SCUP, 16-23 June, Miami, Florida. Typescript.

Pijl, S., Meijer, C. \& Hegarty, S. (1997) Inclusive education. A global agenda. London, Routledge.

Proshansky, H., Fabian, A. K. \& Kaminoff, R. (1983) Place-identity: Physical world socialization of the self. Journal of Environmental Psychology 3(1), pp. 57-83. DOI: 10.1016/S0272-4944(83)80021-8

Quaroni, L. (1977) Progettare un edificio. Otto lezioni di architettura. Rome, Gangemi.

Rilling, J., Gutman, D. A., Zeh, T. R., Pagnoni, G., Berns, G. S. \& Kilts, C. D. (2002) A neural basis for social cooperation. Neuron, 35(2), pp. 395-405. DOI: 10.1016/S0896-6273(02)00755-9

Russell, J. A. \& Pratt, G. (1980) A description of the affective quality attributed to environments. Journal of Personality and Social Psychology, 38(2), pp. 311-322. DOI: 10.1037/0022-3514.38.2.311

Sanoff, H. (1994) School design. New York, John Wiley \& Sons.

Schelle, K. (1802) Die Spatziergänge oder die Kunst spatzieren zu gehen. Leipzig, Martini.

Sommer, R. (1969) Personal space. The behavioral basis of design. Englewood Cliffs, NJ, Prentice-Hall.

Speake, J., Edmonson, S. \& Nawaz, H. (2013) Everyday encounters with nature: Students' perceptions and use of university campus green spaces. Human Geographies - Journal of Studies and Research in Human Geography, 7(1), pp. 21-31. DOI: 10.5719/hgeo.2013.71.21

Steel, E. \& Janeslätt, G. (2017) Drafting standards on cognitive accessibility: A global collaboration. Disability and Rehabilitation: Assistive Technology, 12(4), pp. 385-389. DOI: 10.1080/17483107.2016.1176260

Surtz, E. (1953) St. Thomas More and His Utopian Embassy of 1515. The Catholic Historical Review, 39(3), pp. 272-297.

Thompson, C. W. (2010) Linking landscape and health: The recurring theme. Landscape and Urban Planning, 99(3), pp. 187-195. DOI: 10.1016/j.landurbplan.2010.10.006

Turner, P. V. (1984) Campus: An American planning tradition. Cambridge, MIT Press. DOI: 10.1126/science.225.4664.786-a

Ulrich, R., Simons, R.F., Losito, B. D., Fiorito, E., Miles, M. A. \& Zelson, M. (1991) Stress recovery during exposure to natural and urban environments. Journal of Environmental Psychology, 11, pp. 201-230. DOI: 10.1016/S0272-4944(05)80184-7

Weinberger, A., Christensen, A. P., Coburn, A. \& Chatterjee, A. (2021) Psychological responses to buildings and natural landscapes. Journal of Environmental Psychology, 77, 101676. DOI: 10.1016/j.jenvp.2021.101676

Winerman, L. (2004) Designing psychologists. Monitor on Psychology, 35(7), pp. 1-30. DOI: 10.1037/e384032004-020

Whitmer, S. (2009) Does place really matter to students with learning disabilities? A study of three university campuses. Open House International, 34(1), pp. 75-81. DOI: 10.1108/OHI-01-2009-B0009

Worringer, W. (1959) Abstraktion und Einfühlung. Munich, Piper. 